\title{
Toward an all-inclusive trauma system in Central South Ontario: development of the Trauma- System Performance Improvement and Knowledge Exchange (T-SPIKE) project
}

\author{
Paul T. Engels, MD \\ Angela Coates, MEd \\ Russell D. MacDonald, MD, MPH \\ Mahvareh Ahghari, MEng \\ Michelle Welsford, MD \\ Tim Dodd, ACP \\ Katie Turcotte \\ Jeffrey D. Doyle, MD \\ Arthur M. Eugenio, MD \\ Jason P. Green, MD \\ J. Eric Irvine, MD \\ Paul J. Lysecki, MD \\ Simerpreet K. Sandhanwalia, MD \\ Sunjay V. Sharma, MD, MSc
}

Presented at the Trauma Association of Canada virtual annual scientific meeting and conference, Nov. 16-20, 2020

Accepted Mar. 30, 2020

\section{Correspondence to:}

P. Engels

Hamilton General Hospital

6 North Wing, Room 617

237 Barton St E

Hamilton ON L8L 2X2

engelsp@mcmaster.ca

DOI: $10.1503 /$ cjs. 000820
Background: There is currently no integrated data system to capture the true burden of injury and its management within Ontario's regional trauma networks (RTNs), largely owing to difficulties in identifying these patients across the multiple health care provider records. Our project represents an iterative effort to create the ability to chart the course of care for all injured patients within the Central South RTN.

Methods: Through broad stakeholder engagement of major health care provider organizations within the Central South RTN, we obtained research ethics board approval and established data-sharing agreements with multiple agencies. We tested identification of trauma cases from Jan. 1 to Dec. 31, 2017, and methods to link patient records between the various echelons of care to identify barriers to linkage and opportunities for administrative solutions.

Results: During 2017, potential trauma cases were identified within ground paramedic services (23107 records), air medical transport services (196 records), referring hospitals (7194 records) and the lead trauma hospital trauma registry (1134 records). Linkage rates for medical records between services ranged from $49 \%$ to $92 \%$.

Conclusion: We successfully conceptualized and provided a preliminary demonstration of an initiative to collect, collate and accurately link primary data from acute trauma care providers for certain patients injured within the Central South RTN. Administration-level changes to the capture and management of trauma data represent the greatest opportunity for improvement.

Contexte : On ne dispose actuellement d'aucun système intégré de gestion des données pour évaluer le fardeau réel des traumatismes et de leur gestion dans les réseaux régionaux de traumatologie (RRT) en Ontario, en bonne partie en raison de la difficulté d'identifier les cas parmi la multiplicité des dossiers d'intervenants médicaux. Notre projet représente un effort itératif pour créer la capacité de cartographier le parcours de soin de tous les polytraumatisés du RRT de la région Centre-Sud.

Méthodes : Grâce à l'engagement général des intervenants des grandes organisations de santé du RRT de la région Centre-Sud, nous avons obtenu l'approbation d'un comité d'éthique de la recherche et conclu des accords de partage des données avec plusieurs agences. Nous avons testé l'identification des cas de traumatologie du

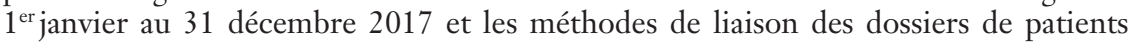
entre les divers échelons de soin pour identifier les obstacles à la liaison et leurs solutions administratives possibles.

Résultats : Au cours de 2017, les cas de traumatologie potentiels ont été identifiés auprès des services ambulanciers terrestres (23107 dossiers), des services de transport médical aérien (196 dossiers), des hôpitaux référents (7194 dossiers) et du registre hospitalier principal de traumatologie (1134 dossiers). Les taux de liaison entre les différents services pour les dossiers médicaux variaient de $49 \%$ à $92 \%$.

Conclusion : Nous avons conceptualisé et présenté avec succès la démonstration préliminaire d'un projet visant à recueillir, colliger et relier avec justesse les données primaires des intervenants en traumatologie aiguë pour certains patients blessés du RRT du Centre-Sud. Des changements administratifs centrés sur la saisie et la gestion des données de traumatologie représentent la meilleure voie vers une amélioration. 
$\mathbf{T}$ raumatic injury represents the leading cause of morbidity and mortality in the population aged 1-44 years and requires a substantial amount of health care resources to treat. ${ }^{1,2}$ In Canada, trauma care is provided in a paradigm that involves numerous types of health care providers who function in successive echelons of care, in a network of resources and facilities organized around a level 1 trauma centre. ${ }^{3,4}$ Each facility within the system ideally has an identifiable role based on resources and the needs of the community. To provide trauma care in a cost-effective manner, it is imperative that all facilities providing trauma care cooperate within their trauma system. ${ }^{3,5}$ The ability to assess, analyze and improve the performance of a trauma system depends on the ability to collect comprehensive data that capture the true burden of injury within that system as well as the health care resources used to address it. ${ }^{5}$

Trauma system organization in Canada is done on a provincial level. In Ontario, a Canadian province with almost 15 million residents, the Ministry of Health $(\mathrm{MOH})$ formally designated lead trauma hospitals (LTHs) - the equivalent of level 1 trauma centres in the United States - across the province in 1990 and attempted to develop effective regional trauma networks (RTNs). ${ }^{5}$ However, for a variety of reasons, the efforts were unsuccessful. ${ }^{5}$ Nevertheless, in 2015, the $\mathrm{MOH}$ initiated a program to establish all-inclusive trauma system organization. ${ }^{6,7}$ These recent efforts have seen the creation of RTNs across the province with the aim of creating all-inclusive trauma systems within these RTNs. ${ }^{6}$ The Central South RTN was created in 2015 as a pilot in combination with the Champlain RTN.7 Implementation of an additional 9 RTNs covering the entire province is currently underway.

Implementation of all-inclusive trauma systems has been shown to improve care $;^{8-11}$ however, it can take up to a decade to yield mortality benefits. ${ }^{12}$ Furthermore, the ability to meaningfully assess the overall performance of a trauma system is still largely elusive, as shown by the numerous reports describing the lack of knowledge in this area. ${ }^{13-16}$ Interestingly, the concept of establishing RTNs as a management-auditing initiative in Ontario was described by $\mathrm{Caro}^{5}$ in 1997. In this sentinel paper, Caro described the use of management auditing as an essential component for the effective delivery of emergent trauma care. However, such an auditing capability is predicated on the existence of well-integrated information systems that produce valid, reliable information in a timely way to support regional management needs. As described by Caro, ${ }^{5}$ a management audit of an RTN is an audit "that assesses the extent to which financial, human and physical resources and services are managed economically, efficiently and effectively. ... Such an audit would determine whether any management actions are indicated on a regional level that could further reduce trauma deaths and injuries."
At present, Ontario does not have trauma systems or networks that have the ability to perform a true management audit, primarily owing to lack of integrated data systems. Most existing trauma system studies are based on data contained within trauma registries, but even the best trauma registries may fail to capture up to $40 \%$ of severely injured patients. ${ }^{17} \mathrm{~A}$ PubMed literature search using the terms "trauma[MESH]" and "[Ontario[TITLE]" identified several papers published since 1995 on the performance of Ontario's trauma centres and systems, ${ }^{18-28}$ but none of them used truly comprehensive data sets representing all trauma care provided in the system. None of these data sets contained the comprehensive information from ground and air medical paramedic services, possibly owing to historical difficulties with linking these data accurately to established and verified data sets.

Multinational initiatives such as the Trauma Quality Improvement Project of the American College of Surgeons Committee on Trauma, ${ }^{29}$ as well as a recent report from the US National Academies of Science, Engineering, and Medicine ${ }^{30}$ espouse the importance of accurate and comprehensive data collection in order to inform improving care. The Trauma-System Performance Improvement and Knowledge Exchange (T-SPIKE) initiative was born out of the need to obtain accurate patient-level data that included all patients injured within an RTN and that spanned the patient's entire journey from scene of injury to acute hospital discharge. The Central South RTN has a population of 2.5 million people and includes 9 separate emergency medical services and 22 hospitals. Hamilton General Hospital is the MOH-designated adult LTH. The Central South RTN encompasses several thousand square kilometres, and paramedic transportation services include ground and rotary-wing.

Through broad stakeholder engagement, and facilitated by recent progression to electronic paramedic medical records, the T-SPIKE investigators endeavoured to create a complete, comprehensive record of care for all patients admitted to hospital for trauma care in the Central South RTN. We hypothesized that creation of a "master" patient record within our RTN is possible. Furthermore, we believe this will open the door to obtaining more contemporaneous, accurate and meaningful information about traumatic injury and its management, thereby enabling us to initiate powerful efforts to improve and optimize care of patients with trauma within our RTN, and serve as a model for others in Ontario and beyond.

The objectives of the present study were to: 1) describe the development and preliminary results of an initiative to collect, collate and accurately link primary data from acute trauma care providers for certain patients injured within the Central South RTN; and 2) identify barriers, gaps, challenges and potential solutions in the creation of such a comprehensive trauma data system. 


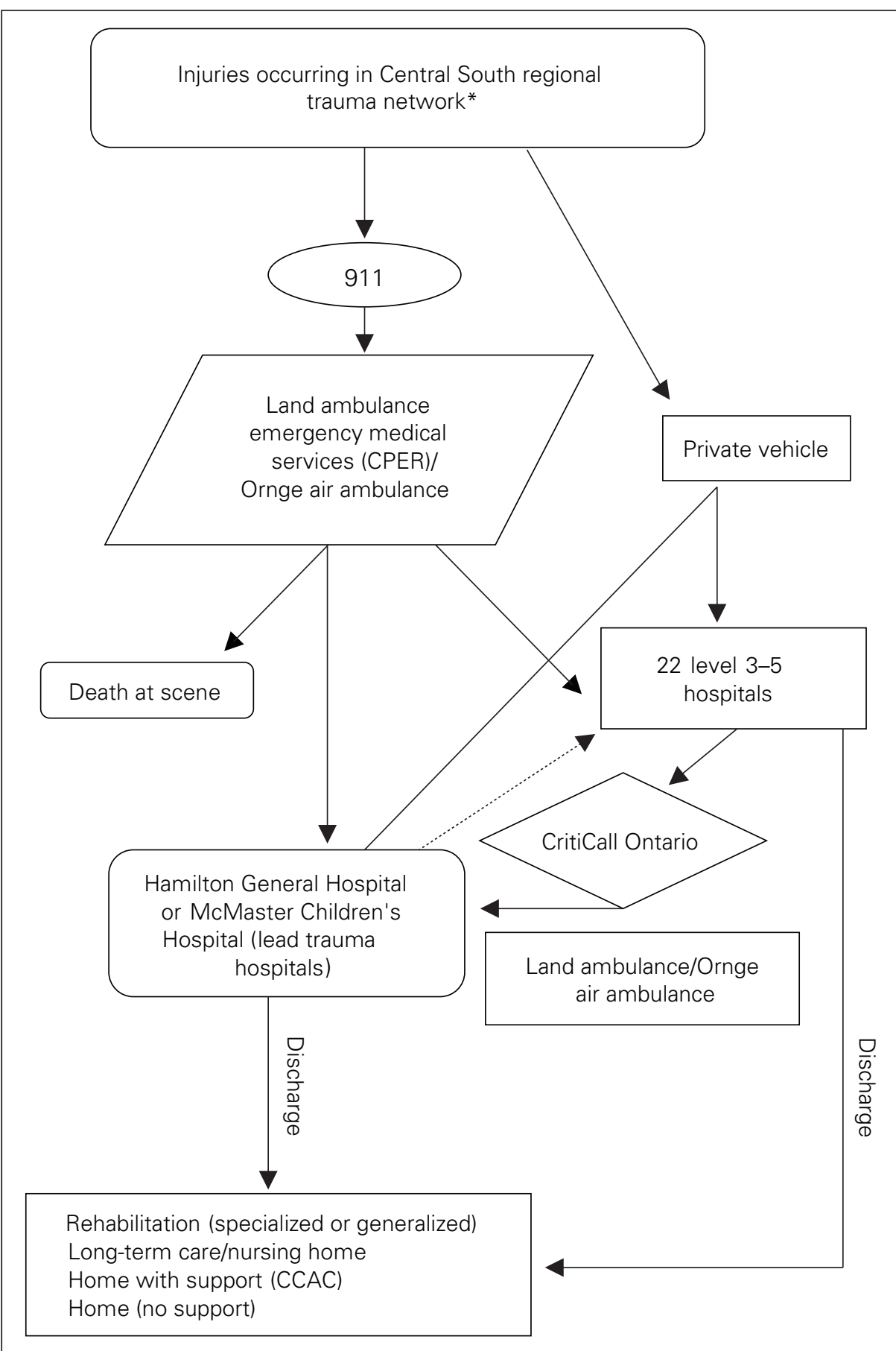

Fig. 1. Ontario Central South regional trauma network. There are 3 types of transfers: scene calls (land ambulance or Ornge air ambulance responds to the scene of an incident and transports the patient directly to a trauma centre); interfacility transfers (the patient is transported by land ambulance or Ornge air ambulance from a level 3,4 or 5 hospital to a lead trauma hospital [LTH]); and modified scene calls (land ambulance transports the patient to the nearest hospital, where it is met by the Ornge air ambulance transport team, who transfer the patient to an LTH). The dashed line represents either repatriation, in which the patient returns to the transferring hospital, or interfacility transfer, in which the patient returns to his or her home hospital (for patients transported directly from the scene to an LTH or transferred to an LTH from a hospital other than the home hospital). *Waterloo Wellington Local Health Integration Network (LHIN), Hamilton Niagara Haldimand Brant LHIN and Halton portion of Mississauga Halton LHIN. CCAC = Community Care Access Centre; CPER = Centre for Paramedic Education and Research.

\section{Methods}

Figure 1 provides a representation of the journey of care that an injured patient in the trauma system may experience. The development of partnerships with our broad network of stakeholders at various institutions and services providing trauma care was an integral step in obtaining research ethics board approval and executing data-sharing agreements with all our major partners. Data sought included patient demographic characteristics, details of all injuries and medical treatment provided, and details on patient transportation, including timing, from Jan. 1 to Dec. 31, 2017. The data queries were created by the lead study data analyst (A.C.) in partnership with each organization and were customized to accommodate the individual characteristics of each data source.

\section{Data sources}

\section{Ground paramedic services}

There is no centralized paramedic service in Ontario. Ground paramedic services for patients with trauma in the Central South RTN are provided by 9 separate services. Recently, all services have migrated to electronic ambulance call records and have been collated into a centralized database, termed the Paramedic Ground Services Regional Database. The Centre for Paramedic Education and Research is an organization linked with Hamilton Health Sciences with a mandate to promote outstanding prehospital care through innovation and excellence in medical oversight and research. Our study team worked with the centre's leadership and data analysts to define a feasible cohort for study.

No mutually exclusive data field(s) exist for paramedic 
services to identify "trauma" reliably (Table 1). Documentation is at the discretion of the responding crew. Paramedics use trauma triage guidelines to identify patients best managed by direct transport to the LTH. We tested several iterations of the original data query and adapted them to maximize sensitivity and specificity in identifying trauma cases. Approval for this portion of the study was obtained from the Hamilton Integrated Research Ethics Board. A data-sharing agreement was separately negotiated between Hamilton Health Sciences and the Centre for Paramedic Education and Research.

\section{Ornge}

Ornge is the exclusive provider of air medical transport within the province of Ontario. Their helicopters, fixedwing aircraft and air medical crews provide primary response and on-scene care, as well as interfacility transport between hospitals and the LTH. Our study team worked with Ornge's leadership and data analysts to create a cohort of all patients identified as "injured" or "trauma," as per their data definitions, who were treated within our RTN, including those who died at the scene (Table 2). Approval for this portion of the study was obtained from Ornge. A data-sharing agreement was negotiated separately between Hamilton Health Sciences and Ornge.

\section{CritiCall Ontario}

CritiCall Ontario is the government-designated organization that provides 24-hour emergency consultation and referral service for physicians at hospitals across the province. It serves as the single point of contact for the request for consultation and transfer of patients with trauma between facilities within the province. CritiCall Ontario is a repository for data that include the time at which a facility initiates the transfer process for a patient, as well as other details about the transport arrangement and any consultation advice and recommendations. At the time of this study, CritiCall Ontario was not able to contribute data to any research studies owing to unresolved concerns about Personal Health Information Privacy Act compliance with such a contribution.

\section{Hamilton General Hospital trauma registry}

Hamilton General Hospital is part of the Hamilton Health Sciences network of hospitals. It maintains an $\mathrm{MOH}-$ mandated registry of all patients with trauma admitted to Hamilton General Hospital who have an Injury Severity Score of 12 or greater, or for whom trauma team activation was initiated. Data elements are abstracted from hospital charts and reported to the Ontario Trauma Registry (Table 3). Approval for this portion of the study was obtained from the Hamilton Integrated Research Ethics Board.

\begin{tabular}{|c|c|}
\hline Characteristic & Description \\
\hline Population & $\begin{array}{l}\text { CPER receives data from the ambulance call report from the service operator in electronic format for integration into } \\
\text { the CPER database. Scope includes emergency medical operators in the Western Region of the province. Seven of } \\
9 \text { regions are represented in our study cohort. }\end{array}$ \\
\hline \multicolumn{2}{|l|}{ Eligibility criteria } \\
\hline Query 1 & $\begin{array}{l}\text { "Trauma injury site/type" is populated (minimum } 1 \text { cell valued); and problem code = musculoskeletal/trauma (ambulance } \\
\text { call report code } 66 \text { or 67); and special transport code }=1 \text { of the } 3 \text { field trauma triage transport codes; and not ST-elevation } \\
\text { myocardial infarction or stroke; and minimum } 1 \text { of the following: hospital 4-digit code is entered (i.e., "receiving facility" is } \\
\text { populated); patient deceased; patient transported by another ambulance. }\end{array}$ \\
\hline Final query & $\begin{array}{l}\text { If assessment of iteration } 1 \text { showed that "problem code" and "trauma injury site/type" were inconsistent or incomplete, } \\
\text { these fields were removed from the query. }\end{array}$ \\
\hline Data & $\begin{array}{l}\text { - Basic patient demographic characteristics (name, age, sex) } \\
\text { - Call number and date } \\
\text { - Primary problem code } \\
\text { - Final primary problem code } \\
\text { - Emergency medical service code } \\
\text { - Injury type and location codes } \\
\text { - Mechanism of injury code } \\
\text { - Nonoperative procedures (cardiopulmonary resuscitation, shock) } \\
\text { - Dispatch priority } \\
\text { - Return priority } \\
\text { - Receiving hospital code } \\
\text { - Time stamps (dates and times of occurrence; call received, crew notified; crew mobile; arrive scene; arrive patient; } \\
\text { depart scene; arrive destination; depart destination) }\end{array}$ \\
\hline $\begin{array}{l}\text { Indirect identifiers for linkage } \\
\text { across data sources }\end{array}$ & Patient's name/initials, date of birth and sex, call date, receiving facility code. \\
\hline
\end{tabular}




\begin{tabular}{|c|c|}
\hline Characteristic & Description \\
\hline Population & $\begin{array}{l}\text { Emergent and urgent transport of critically injured patients by Ornge (air and land); includes transport from scene, } \\
\text { interfacility transfer and modified scene }\end{array}$ \\
\hline Eligibility criteria & $\begin{array}{l}\text { Type of transfer = trauma; AND pick-up location (scene or sending facility) located in Waterloo Wellington LHIN, Hamilton } \\
\text { Niagara Haldimand Brant LHIN or Halton portion of Mississauga Halton LHIN; OR receiving facility = Hamilton General } \\
\text { Hospital or McMaster Children's Hospital }\end{array}$ \\
\hline Data & $\begin{array}{l}\text { - Basic patient demographic characteristics (age, sex) } \\
\text { - Call type/scene, interfacility transfers and modified scene } \\
\text { - Level of priority (dispatch priority, return priority, Canadian Triage and Acuity Scale return priority) } \\
\text { - Pick-up location (scene/address, hospital) } \\
\text { - Receiving hospital } \\
\text { - Vehicle type (Ornge land ambulance, helicopter, local emergency medical service) } \\
\text { - Crew (number and configuration) } \\
\text { - Time stamps (call accepted, time call accepted, depart base, time depart base, arrive pick-up landing, arrive time pick-up } \\
\text { landing, arrive patient site, arrive time patient site, depart patient site, depart time patient site, depart landing site, } \\
\text { depart time landing site, arrive destination land site, arrive time destination land site, transfer care, time transfer care, } \\
\text { depart delivery site, time depart delivery site, arrive base, time arrive base) }\end{array}$ \\
\hline $\begin{array}{l}\text { Indirect identifiers for linkage across } \\
\text { data sources }\end{array}$ & Patient's name/initials, date of birth and sex, call date, sending facility code, receiving facility code \\
\hline
\end{tabular}

Table 3. Characteristics of the Hamilton General Hospital trauma registry data set

\begin{tabular}{|c|c|}
\hline Characteristic & Description \\
\hline Population & $\begin{array}{l}\text { The Ontario Trauma Registry Comprehensive Data Set consists of detailed information on patients with major trauma } \\
\text { who present to lead trauma hospitals across Ontario. }\end{array}$ \\
\hline Eligibility criteria & $\begin{array}{l}\text { Case inclusion/trauma definition: patients with an Injury Severity Score } \geq 12 \text { (Abbreviated Injury Scale 2005), AND an ICD } \\
\text { code for external cause of injury that meets the definition of trauma in the Ontario Trauma Registry (e.g., external cause } \\
\text { of injury codes that are included in the definition of trauma are motor vehicle collisions, including those involving } \\
\text { pedestrians, motorcycles and bicycles, falls, drowning and burns; exclusions are poisoning, adverse effects and } \\
\text { complications); is admitted or is treated in the emergency department but not admitted; or died in the emergency } \\
\text { department. All patients with trauma team activation are included regardless of their Injury Severity Score. }\end{array}$ \\
\hline \multirow[t]{9}{*}{ Data } & - Basic patient demographic characteristics (age, sex) \\
\hline & - Injury data, including mechanism of injury \\
\hline & - Scene data, including mode of transport, crew, time stamps (e.g., crew arrival on scene) \\
\hline & - Procedures performed on scene \\
\hline & - Sending hospital data (where applicable), including nonoperative and operative procedures \\
\hline & - LTH care (intensive care unit, surgical interventions, physician services involved in care) \\
\hline & - Anatomic diagnoses (Injury Severity Score) \\
\hline & - Patient complications, comorbidities \\
\hline & - Patient outcomes (length of stay, discharge disposition, death) \\
\hline $\begin{array}{l}\text { Indirect identifiers for linkage across } \\
\text { data sources }\end{array}$ & Patient's name/initials, date of birth and sex, arrival at LTH, sending facility code (where applicable). \\
\hline
\end{tabular}

\section{Self-identified level 3 hospitals}

Eight of the 22 hospitals in the Central South RTN are self-identified level 3 trauma centres ("self-identified" because, outside of the LTHs, the MOH has not designated any other hospital trauma centres). Functionally, the 8 hospitals are moderate-size facilities with 24-hour emergency departments and surgical capabilities that typically receive patients with trauma from ground paramedic services in cases in which the road travel time from the location of injury to Hamilton General Hospital would exceed 30 minutes, in compliance with field trauma triage standards at the time of this study. ${ }^{31}$ These hospitals can treat and discharge the patient, treat and admit the patient (sometimes with consultation advice from CritiCall Ontario), treat and transfer the patient to the LTH (via
CritiCall Ontario) or act as a modified scene base, in which case Ornge paramedics use the local helipad or hospital emergency department to take handover of care from the ground paramedics to prepare the patient for rotary-wing transport.

As the formal designation of level 3 hospitals represents the biggest potential change to the patient flow and care processes within the Central South RTN, for our initial T-SPIKE project, we chose to focus on the hospitals that had the potential to become level 3 centres. For each hospital, a local investigator was identified as the emergency department representative at the RTN and was approached to participate in the study. We obtained approval via the respective research ethics boards and established data-sharing agreements with 10 of the 
22 hospitals in the Central South RTN (the 8 selfidentified level 3 hospitals and 2 smaller hospitals).

The self-identified level 3 trauma centres do not specifically report any trauma cases to the government or the Hamilton General Hospital trauma registry. Patients who are subsequently transferred to Hamilton General Hospital would generally be captured by the hospital's trauma registry; patients admitted to and kept at the local hospital would not be identified in the registry. To identify any patients with trauma at the self-identified level 3 hospitals, a query was run through each hospital's health records department to identify all adult and pediatric patients with any diagnosis of an injury (International Statistical Classification of Diseases and Related Health Problems, 10 Revision codes S00 to T79) who presented to the emergency department and were admitted to that hospital, died in the emergency department or were transferred to Hamilton General Hospital (Table 4).

\section{Data linkage}

Data were transmitted to the study investigators at Hamilton General Hospital via appropriate methods as dictated by the respective research ethics boards and data-sharing agreements. Each data set was examined for inclusion/ exclusion criteria according to our data request and query definitions. We used frequency distributions to understand data formats and to identify rates of missing data, errant values and outliers. Data cleaning included such tasks as removing unwanted spaces, punctuation, numbers and strange symbols. Records with odd values were corrected where possible, or the odd values were replaced with missing values. Data format was standardized, focusing primarily on formats for the data fields to be used for linkage. All fields were standardized according to type (e.g., date, time, numeric, character) and length.

Data linkage in this context involves bringing together 2 or more pieces of information that relate to the same patient, thus providing the ability to describe relations between factors that are not evident from a single source. Understanding each data set is imperative at the outset of data linkage.

A number of techniques are available for data linkage. When direct identifiers are available and are of good quality, deterministic methods are recommended..$^{32}$ For example, deterministic linkage is possible when a unique identifier is shared between 2 data sources, provided that the linkage field is unique and accurate. Deterministic linkage is easy to use when it gives positive results. However, increasingly restrictive policies surrounding the release of data limit access to unique identifiers.

An alternative method, probabilistic linkage, compares variables between data sets and results in a decision as to whether the records do or do not belong to the same person. This approach tends to be more tolerant of data errors and can outperform deterministic methods. However, it requires additional time and resources to complete. $^{32}$

\begin{tabular}{|c|c|}
\hline Characteristic & Description \\
\hline Population & $\begin{array}{l}\text { The Central South RTN encompasses the Waterloo Wellington LHIN, the Hamilton Niagara Haldimand Brant LHIN and the } \\
\text { Halton portion of the Mississauga Halton LHIN. There is } 1 \text { adult level } 1 \text { trauma centre, located at Hamilton General } \\
\text { Hospital, and } 1 \text { pediatric trauma centre, at McMaster Children's Hospital. Critically injured patients taken to } 1 \text { of the } \\
22 \text { hospitals self-designated as level 3-5 may be transferred to } 1 \text { of the LTHs. Patients who die at the scene, are admitted } \\
\text { to hospital or die at a level 3-5 hospital are not part of the Hamilton General Hospital trauma registry. Trauma activation } \\
\text { guidelines, together with individual circumstances and clinical judgment (sending hospital and trauma team leader), } \\
\text { determine transfers. }\end{array}$ \\
\hline Eligibility criteria & $\begin{array}{l}\text { All patients who present to a level 3-5 hospital emergency department with at least } 1 \text { ICD-10 diagnosis code indicative of } \\
\text { an injury or burn (ICD-10 code S00 to T79). }\end{array}$ \\
\hline \multicolumn{2}{|l|}{ Data } \\
\hline Patient & $\begin{array}{l}\text { - Basic demographic characteristics (name/initials, age, sex) } \\
\text { - Mode of arrival (e.g., ambulance, air ambulance, walk-in) } \\
\text { - Admission date } \\
\text { - Interventions performed (surgical, diagnostic imaging) } \\
\text { - List of ICD-10 injury diagnosis codes (codes S00 to T79 only) } \\
\text { - Discharge status/disposition (e.g., home, transfer to another hospital, death) } \\
\text { - Date and time of discharge or death }\end{array}$ \\
\hline $\begin{array}{l}\text { Hospital administrative data } \\
\text { sources }\end{array}$ & $\begin{array}{l}\text { - Discharge Abstract Database captures administrative, clinical and demographic information on hospital discharges } \\
\text { (including deaths, sign-outs and transfers) } \\
\text { - National Ambulatory Care Reporting System contains data for all hospital- and community-based ambulatory care (e.g., } \\
\text { emergency department) }\end{array}$ \\
\hline $\begin{array}{l}\text { Indirect identifiers for linkage across } \\
\text { data sources }\end{array}$ & $\begin{array}{l}\text { Patient's name/initials, date of birth/age and sex, hospital code, date/time of arrival, emergency department disposition } \\
\text { (admitted to hospital, transferred to another acute care facility, death in emergency department) }\end{array}$ \\
\hline
\end{tabular}


Our pilot work showed that there was no single unique identifier to link all trauma data sources, resulting in the need to use probabilistic linkage (unpublished observations, 2016). We used combinations of indirect identifiers (e.g., name or initials, date of birth, sex, service dates and times [e.g., date and time of arrival at hospital]) to formulate linkage identifiers across system care providers. We used an iterative process, employing additional algorithms coupled with combinations of data elements between data sets, using both forward and backward linkage methods. After completing the initial linkage, we reviewed a random sample of linkage decisions to ensure that the algorithms performed as intended. This process revealed opportunities to refine and adjust our approach. For example, to accommodate patients whose journey from the scene of injury to arrival at an LTH began on one day and continued into another (i.e., crossed midnight), we reevaluated records using a "plus/minus 1 day" algorithm.

We used blocking to limit comparisons to records that shared a minimum level of identifying information. ${ }^{33}$ Essentially, blocking minimizes "noise" and allows only records that agree on a specific field(s) to be compared. A key component of our blocking strategy was the use of hospital codes. We created fields in all records to store a unique 4-digit hospital code (i.e., each record in each primary hospital cohort included a field that stored a code for the primary hospital and, if applicable, a code for the hospital to which the patient was transferred). We introduced similar hospital codes into the paramedic and Ornge data sets. These codes were instrumental in blocking. When dealing with primary hospital cohorts, we created a block of cases with only those records that identified the patient as having been transferred to Hamilton General Hospital or McMaster Children's Hospital, the pediatric LTH in the Central South RTN. Similar blocks were used for paramedic and Ornge transfers.

We used direct visual matching, or manual linkage, to supplement electronic matching and improve linkage rates.

\section{Statistical analysis}

The quality of linkage methods can be evaluated in many ways. For the purposes of this demonstration project, we focused on true matches to establish, or piece together, the patient's journey. Given that rates of false-negative matches (a true match's not being recognized) and falsepositive matches ( 2 records identified as a match, when they are not) are important in evaluating linkage results, we concentrated our efforts on methods and identification of data gaps. ${ }^{34}$ For example, we expected that all records for patients transferred from a given hospital to an LTH should be included in that hospital's block and should link to the Hamilton General Hospital trauma registry. Where possible, we evaluated linkages at both ends of the linkage process. For example, we assessed the records of patients identified in the trauma registry as having been being transferred from a given hospital to see how many could be linked to the cohort received from that hospital.

\section{Results}

During the study period, the 10 participating hospitals identified 7194 patients who were admitted, died or were transferred to another facility. Of the 7194, 1900 selfpresented, and 5294 arrived via ground paramedics or Ornge to a non-LTH hospital. A total of 6341 patients were admitted, 40 died in the emergency department, and 813 were transferred to another acute care facility (Figure 2). Of the 813 patients identified as having been transported to another acute care facility, 297 (36.5\%) were identified as having been transferred to an LTH within the RTN. We were able to link half of these records (148/297 [49.8\%]) to the Hamilton General Hospital trauma registry, or the emergency department or admission record. The trauma registry logged 1134 adult and pediatric cases during the study period.

Paramedic services provided 23107 records, of which $15152(65.6 \%)$ had a primary problem code identified as musculoskeletal or trauma, and more than $90 \%$ had a primary problem code consistent with mechanism of injury codes used by Ontario Trauma Registry (e.g., fall, assault, motor vehicle collision). Owing to the inclusiveness of this cohort, we could assess only 1-way linkage. Rates of linkage between paramedic records and referral hospital records for cases of patients transported from the scene to a referral hospital in our catchment area ranged from $49.0 \%$ to $60.2 \%$. According to the Hamilton General Hospital trauma registry, paramedic services transported 540 patients directly from the scene to an LTH. The rate of linkage between paramedic records and the trauma registry for this group was $59.4 \%$ (321/540).

Ornge identified 196 records with a pick-up or sending hospital location in the Central South RTN catchment area. In 41 cases, Ornge was dispatched to the scene. Twenty-eight patients were transported to an LTH in the Central South RTN; 26 of the 28 records were linked to the Hamilton General Hospital trauma registry. Ten patients were taken to an LTH outside the Central South RTN, and 3 patients were not transported by Ornge.

A total of 155 Ornge records were interfacility transfers or modified scene calls; 130 of the 155 patients were transported to an LTH in the Central South RTN. Records for 120 of these cases $(92.3 \%)$ were linked to the Hamilton General Hospital trauma registry. Of the remaining 25 patients, 23 were transported to an LTH outside the Central South RTN, and 2 were not transported by Ornge. The overall rate of linkage of Ornge records to Hamilton General Hospital trauma registry records was $92.4 \%(146 / 158)$. 


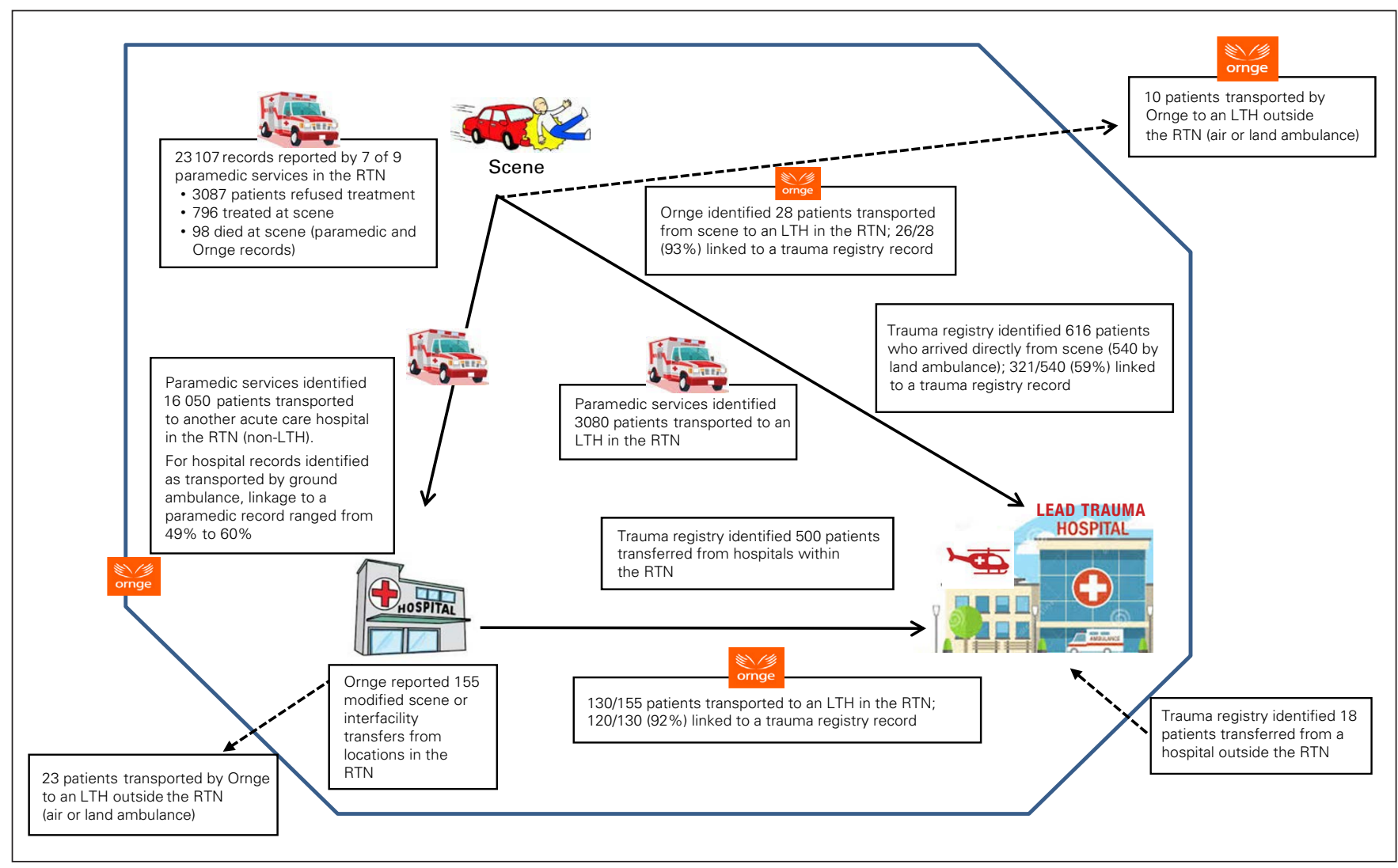

Fig. 2. Medical record linkage throughout care journey of patients with trauma within the Central South regional trauma network (RTN), Jan. 1 to Dec. 31, 2017. LTH = lead trauma hospital.

The 10 participating hospitals transferred 307 (61.4\%) of the 500 patients transferred to an LTH during the study.

Cases missing on a hospital's list signalled potential problems with the query to identify cases at the hospital level or coding errors (e.g., transfer to another acute care hospital not captured accurately), whereas unmatched records identified a potential problem with the linkage algorithm.

\section{Discussion}

The T-SPIKE initiative represents an evolution in the collection, collation, linkage and validation of trauma care data in a major Canadian trauma system. Our study shows a successful method to create an integrated trauma care record that reflects all aspects of acute trauma care provided in the Central South RTN. However, our linkage rates also substantiate that important work remains in order to make this data set truly comprehensive. The considerable expenditure of resources and the necessity of substantial direct human involvement in the linkage processes make this approach unsustainable in the long term, both for the Central South RTN and for any others.

Although numerous other studies have been conducted to attempt to evaluate trauma care on a system level in
Ontario, ${ }^{18-28}$ none of these studies were able to provide a true management audit of the entire trauma system owing to the limitations of their data sets. Our study represents an important step forward on the path to developing the capacity to provide such an audit of the trauma system as envisioned by Caro. ${ }^{5}$

As stated by Critical Care Services Ontario, the mandate of the RTNs is to "establish a quality-assurance process for trauma-care improvement locally, regionally and provincially." 6 Therefore, any future trauma system management audits need to be conducted specific to the RTN and not on the entire province or on a single type of trauma care provider (e.g., emergency department, inpatient hospital care, helicopter transport) in isolation. The integration of relevant, valid and reliable management information is vital to create robust quality-assurance and performance-improvement processes.

Our work identified administrative and system-based barriers to the creation of an integrated trauma care record, and efforts to be focused on overcoming these. Engagement with the health care system's administrative leaders, with clear goals and strategies to improve the ability to identify, track and link patients with trauma within our RTN, will be key. In particular, implementation of a first-point-of-contact unique identifier that would exist in perpetuity and be promulgated throughout the patient's 
continuum of care (and patient care records) represents the greatest opportunity to address the existing linkage barriers and should be achievable within the paradigm of publicly funded and administered health care in Canada.

From a qualitative perspective, we identified a number of barriers to successfully linking all patient records. First, there are no existing data-sharing agreements or similarly functioning administrative agreements to share data between trauma care providers in the RTN outside of those created for research purposes (e.g., our current study). Second, identification of patients with trauma from ground paramedic service records proved to be very challenging, as no standard designation for such a patient type exists, in contrast to patients with an acute cardiac or stroke presentation. Given the magnitude of paramedic service involvement in trauma care, the limitations of this source of data carry considerable downstream impact. Third, there does not currently exist any reliable method to deterministically link a patient's medical records between echelons of care; patient identifiers are frequently incomplete or inaccurate, and, thus, probabilistic linkage must be used.

Although existing administrative data sets offer insights into patient care issues, their view is often too high-level to precisely identify the opportunity for improvement. During the initial RTN pilot in Central South Ontario, efforts were made to collect data on Critical Care Services Ontario performance indicators such as referring hospital time-to-transfer. Although we had access to multiple administrative data sets, we were unable to determine where the delays actually existed. This ambiguity and lack of detail critically impede the ability to focus efforts on the correct component of the problem. For example, in a study of patient transfer timeliness for helicopter emergency medical services in southwestern Ontario, the reason for the transport delays was traced to a lack of helipads adjacent to the requesting facility, which necessitated additional ambulance transfers to and from the facility. ${ }^{35}$ Without such detailed data and robust analysis, it would have been easy to ascribe the transport delay to the helicopter emergency medical service or the health care providers at the sending facility rather than to the helipad locations.

The creation of a comprehensive master patient record for all patients with trauma in the Central South RTN will allow for a clearer understanding of the burden of injury in the system, as well as the resources currently being used and how they being implemented to provide trauma care. It also will provide an opportunity to apply quality- and performance-improvement analyses to effectively target interventions to make a high-impact change that has a positive outcome for a large number of patients. Other Canadian provinces have already implemented all-inclusive trauma systems, ${ }^{36-38}$ with demonstrated positive effects. ${ }^{11}$ Reports from these systems routinely include data from level 3 centres, and such reports are able to describe the burden of injury, resources deployed and patient outcomes for each region, as well as for the province overall. A common theme in their development was the formal designation of level 1,2 and 3 hospitals, and the conscious recruitment of trauma directors, trauma managers and data analysts at all sites.

Our successful demonstration of proof-of-concept of a validated linkage methodology will allow the Central South RTN to start limited management auditing analyses, and provides a model of a potentially exportable and scalable template to the other provincial RTNs and beyond.

\section{Limitations}

Our study did not include data from the Ontario Coroner's Office or CritiCall Ontario, direct data from the Central Ambulance Communication Centre or data on care provided after discharge from an acute care hospital. Data from ground paramedic services across the RTN represented 7 of 9 services; which likely resulted in underestimation of the linkage rates between individual hospitals and the Hamilton General Hospital trauma registry. Although we did not obtain data directly from the Central Ambulance Communication Centre, the data obtained from the Paramedic Ground Services Regional Database and Ornge included the Central Ambulance Communication Centre data. The lack of data on patients after their discharge from an acute care hospital also means that we did not know their use of rehabilitation, community and reintegration services, or their long-term neurologic and functional outcomes.

\section{Conclusion}

We successfully conceptualized and provided a preliminary demonstration of an initiative to collect, collate and accurately link primary data from acute trauma care providers for certain patients injured within the Central South RTN in Ontario. However, the inability to achieve linkage for a substantial proportion of patients limits the comprehensiveness of this picture. We identified that the greatest opportunity for creating a comprehensive and evaluable trauma system within an RTN resides with making administrative-level changes to data capture and sharing. We plan to use this linked master data set to begin examining the function of our trauma system and to identify opportunities to improve and optimize trauma care.

Affiliations: From the Department of Surgery, McMaster University, Hamilton, Ont. (Engels, Coates, Doyle, Sharma); the Trauma Program, Hamilton Health Sciences, Hamilton, Ont. (Engels, Coates, Sharma); Ornge, Mississauga, Ont. (MacDonald); the Department of Medicine, University of Toronto, Toronto, Ont. (MacDonald, Ahghari); the Centre for Paramedic Education and Research, Stoney Creek, Ont. (Welsford, Dodd, Turcotte); the 
Division of Emergency Medicine, McMaster University, Hamilton, Ont. (Welsford); Niagara Health, St. Catharines, Ont. (Doyle); Cambridge Memorial Hospital, Cambridge, Ont. (Eugenio); Grand River Hospital, Kitchener-Waterloo, Ont. (Green); Brantford General Hospital, Brantford, Ont. (Irvine); Joseph Brant Hospital, Burlington, Ont. (Lysecki); and Oakville Trafalgar Memorial Hospital, Oakville, Ont. (Sandhanwalia).

Competing interests: None declared.

Contributors: A. Coates, P.T. Engels, S.V. Sharma, R.D. MacDonald and M. Welsford designed the study. A. Coates, S.K. Sandhanwalia and T. Dodd acquired the data, which A. Coates and P.T. Engels analyzed. A. Coates, P.T. Engels and S.V. Sharma wrote the manuscript, which all authors critically revised. All authors gave final approval of the article to be published.

Content licence: This is an Open Access article distributed in accordance with the terms of the Creative Commons Attribution (CC BYNC-ND 4.0) licence, which permits use, distribution and reproduction in any medium, provided that the original publication is properly cited, the use is noncommercial (i.e., research or educational use), and no modifications or adaptations are made. See: https://creativecommons.org/ licenses/by-nc-nd/4.0/.

Funding: This project was supported by an Education Research Grant (2015) and an Innovation Grant (2017) from McMaster Surgical Associates.

\section{References}

1. HCUP facts and figures: statistics on hospital-based care in the United States. Healthcare Cost and Utilization Project (HCUP). Rockville (MD): Agency for Healthcare Research and Quality; 2013. Available: https://www.hcup-us.ahrq.gov/reports/factsandfigures.jsp (accessed 2019 Oct. 1).

2. Cost of injury in Canada. Toronto: Parachute. Available: https:// parachute.ca/en/professional-resource/cost-of-injury-report/ (accessed 2019 Oct. 1).

3. Resources for optimal care of the injured patient. Chicago: American College of Surgeons Committee on Trauma; 2014:1.

4. Trauma system accreditation guidelines. 4th revision. Halifax: Trauma Association of Canada; 2011. Available: https://www.traumacanada. org/wp-content/uploads/2019/05/Accreditation_Guidelines_2011.pdf (accessed 2019 Oct. 1).

5. Caro DH. Toward effective regional trauma networks: management auditing initiatives in Ontario. Health Care Manage Rev 1997;22: 21-32.

6. Regional trauma network development: a guide for Ontario hospitals. Toronto: Critical Care Services Ontario; 2016. Available: https:// criticalcareontario.ca/wp-content/uploads/2020/10/Regional-Trauma -Network-Development-Guide.pdf (accessed 2019 Oct. 1).

7. Keenan A, Klassen B. A tale of two pilots: Ottawa and Hamilton. Trauma Association of Canada annual scientific meeting and conference; 2015 Apr. 10-11; Calgary. Available: https://criticalcareontario. ca/wp-content/uploads/2020/10/RTN-Development-A-Tale-of-Two -Pilots.pdf (accessed 2021 Feb. 19).

8. Nathens AB, Jurkovich GJ, Cummings P, et al. The effect of organized systems of trauma care on motor vehicle crash mortality. FAMA 2000 19;283:1990-4.

9. MacKenzie EJ, Rivara FP, Jurkovich GJ, et al. A national evaluation of the effect of trauma-center care on mortality. N Engl 7 Med 2006; 354:366-78.

10. Gabbe BJ, Simpson PM, Sutherland AM, et al. Improved functional outcomes for major trauma patients in a regionalized, inclusive trauma system. Ann Surg 2012;255:1009-15.

11. Mckee J, Roberts D, van Wijngaarden M, et al. The right treatment at the right time in the right place: a population-based, before-and-after study of outcomes associated with implementation of an all-inclusive trauma system in a large Canadian province. Ann Surg 2015;261:558-64.

12. Nathens AB, Brunet FP, Maier RV. Development of trauma systems and effect on outcomes after injury. Lancet 2004;363: 1794-801.

13. Gruen RL, Gabbe BJ, Stelfox HT, et al. Indicators of the quality of trauma care and the performance of trauma systems. Br 7 Surg 2012; 99(Suppl 1):97-104.

14. Santana MJ, Stelfox HT. Quality indicators used by trauma centres for performance improvement. F Trauma Acute Care Surg 2012;72:1298-1302.

15. Moore L, Champion H, O'Reilly G, et al. Impact of trauma system structure on injury outcomes: a systemic review protocol. Syst Rev 2017;6:12.

16. Moore L, Champion H, Tardif PA, et al. Impact of trauma system structure on injury outcomes: a systematic review and meta-analysis. World 7 Surg 2018;42:1327-39.

17. Newgard CD, Fu R, Lerner EB, et al. Deaths and high-risk trauma patients missed by standard trauma data sources. 7 Trauma Acute Care Surg 2017;83:427-37.

18. Gomez D, Haas B, Larsen K, et al. A novel methodology to characterize interfacility transfer strategies in a trauma transfer network. $\mathcal{F}$ Trauma Acute Care Surg 2016;81:658-65.

19. Gomez D, Alali AS, Haas B, et al. Temporal trends and differences in mortality trauma centres across Ontario from 2005 to 2011: a retrospective cohort study. CMA7 Open 2014;2:E176-82.

20. Macpherson AK, Schull MJ. Penetrating trauma in Ontario emergency departments: a population-based study. CFEM 2007;9:16-20.

21. Mann SM, Banaszek D, Lajkosz K, et al. High-energy trauma patients with pelvic fractures: management trends in Ontario, Canada. Injury 2018;49:1830-40.

22. Lane PL, Goid G, Mikrogianakis A, et al. An evaluation of Ontario trauma outcomes and the development of regional norms for Trauma and Injury Severity Score (TRISS) analysis. 7 Trauma 1996; 41:731-4.

23. Haas B, Doumouras AG, Gomez D, et al. Close to home: an analysis of the relationship between location of residence and location of injury. 7 Trauma Acute Care Surg 2015;78:860-5.

24. Haas B, Stukel TA, Gomez D, et al. The mortality benefit of direct trauma centre transport in a regional trauma system: a populationbased analysis. 7 Trauma Acute Care Surg 2012;72:1510-5.

25. Gomez D, Haas B, Doumouras AG, et al. A population-based analysis of the discrepancy between potential and realized access to trauma centre care. Ann Surg 2013;257:160-5.

26. Merali Z, Sharma S, MacDonald RD, et al. Emergent and urgent transfers to neurosurgical centres in Ontario. Prehosp Emerg Care 2016;20:245-53.

27. Rowe BH, Rowe AM, Bota GW. Bicyclist and environmental factors associated with fatal bicycle-related trauma in Ontario. CMAJ 1995; 152:45-53.

28. Lord S, Tator CH, Wells S. Examining Ontario deaths due to allterrain vehicles, and targets for prevention. Can 7 Neurol Sci 2010;37: 343-9.

29. Trauma Quality Improvement Program (TQIP). Chicago: American College of Surgeons. Available: https://www.facs.org/quality-programs/ trauma/tqip (accessed 2018 Aug. 14).

30. National Academies of Sciences, Engineering, and Medicine. $A$ national trauma care system: integrating military and civilian trauma systems to achieve zero preventable deaths after injury. Washington: National Academies Press; 2016. Available: https://www.nap.edu/ catalog/23511/a-national-trauma-care-system-integrating-military-and -civilian-trauma (accessed 2018 Aug. 12).

31. Field trauma triage and air ambulance utilization standards. Training Bulletin issue 113 - version 1.0. Emergency Health Services Branch, Ministry of Health and Long-Term Care; 2014. Available: www.health.gov.on.ca/en/pro/programs/emergency_health/ docs/ehs_training_blltn113_en.pdf(accessed 2021 Feb. 23). 
32. Newcombe HB. Handbook for record linkage: methods for health and statistical studies, administration and business. New York: Oxford University Press; 1988.

33. Dusetzina SB, Tyree S, Meyer AM, et al. Linking data for health services research. A framework and instructional guide. Report no 14-EHC033-EF. Rockville (MD): Agency for Healthcare Research and Quality; 2014.

34. Boyd JH, Randall SM, Ferrante AM, et al. Accuracy and completeness of patient pathways - the benefits of national data linkage in Australia. BMC Health Serv Res 2015;15:312.

35. Foo CPZ, Ahghari M, MacDonald RD. Use of geographic information systems to determine new helipad locations and improve timely response while mitigating risk of helicopter emergency medical services operations. Prehosp Emerg Care 2010;14:461-8.

36. Alberta Trauma Services annual report 2015-2016. Alberta Health Services. Available: https://www.albertahealthservices.ca/info/ Page16763.aspx (accessed 2020 Feb. 20).

37. Trauma Services BC: executive summary - 2014. Vancouver: Trauma Services BC. Available: www.phsa.ca/our-services-site/ Documents/TSBC\%20Executive\%20Summary\%20-\%202014.pdf (accessed 2020 Feb. 20).

38. Trauma Nova Scotia Registry. Available: https://www.trauma-ns. com/registry (accessed 2020 Feb. 20). 